FACTA UNIVERSITATIS

Series: Mechanical Engineering Vol. 18, No 2, 2020, pp. 329 - 339

https://doi.org/10.22190/FUME180120016M

Original scientific paper

\title{
PREDICTION OF TEMPERATURE DISTRIBUTION IN THE WORM GEAR MESHING
}

\author{
Aleksandar Miltenović ${ }^{1}$, Milan Tica ${ }^{2}$, Milan Banić ${ }^{1}$, Đorđe Miltenović \\ ${ }^{1}$ Faculty of Mechanical Engineering, University of Niš, Serbia \\ ${ }^{2}$ Faculty of Mechanical Engineering, University of Banja Luka, Bosnia and Herzegovina \\ ${ }^{3}$ The College of Textile, Leskovac, Serbia
}

\begin{abstract}
Worm gear transmissions have number of advantages over other types of transmission, allowing them a wide scope of applications for the transfer of power and movement. One of the important advantages of this transmission is the possibility of obtaining a large transmission ratio. The lack of worm gear transmission means a relatively low efficiency, especially for the extreme operating conditions primarily related to the high frequency of rotation. Between the flanks of worm and worm gears there is considerable slippage, which results in wear at the worm gear flank and considerable significant power losses that are converted into heat. The amount of energy that is converted into heat to a large extent is determined by the friction coefficient between the flanks. It is therefore very important to take into consideration the process of tribo-system mesh of flanks and lubricant. The paper presents FEM calculated distribution of transmission temperature based on the data about power losses obtained analytically. The resulting temperature distribution is compared to the experimental research.
\end{abstract}

Key Words: Worm Gear Transmission, Temperature Distribution, FEM, Friction

\section{INTRODUCTION}

The main function of the power transmission is to convert and manage mechanical energy from the drive to the driven machine. The most commonly used are power transmissions with gears; they are used in over $80 \%$ of mechanically transferred energy. In the division of the transmissions it is very important to distinguish transmission with pure rolling from that with helical rolling. The helical rolling transmission, besides pure rolling, has a slip along the lateral line, which results in additional power losses and

Received January 20, 2018 / Accepted April 25, 2019

Corresponding author: Aleksandar Miltenović

University of Niš, Faculty of Mechanical Engineering, A. Medvedeva 14, 18000 Niš, Serbia

E-mail: aleksandar.miltenovic@masfak.ni.ac.rs 
lower efficiency. Worm gears belong to the category of the helical rolling transmission. A high slip between flanks of worm and worm gear leads to high local surface pressure, which requires the use of materials pairs that are resistant to damage form like scuffing. The worm gears have a number of advantages over other types of transmissions, allowing them a wide scope of applications for the transfer of power as well as that of movement. They are used in machine tools, transportation equipment, primarily in power transfer vehicles, as well as precision devices for movement transmission.

Determination of heat generation using FEM can be used in the cases where temperature increase is caused by friction between two materials. Jain et al. [1] show the temperature distribution during the friction stir welding where he has used a thermo-mechanical model based on the Lagrangian incremental technique. Their FEM model can predict temperature, forces and strain distribution.

Haddad et al. [2] present the numerical DEM-FEM coupling approach for determination of thermomechanical parameters of the contact interface. Their numerical approach is used to estimate various parameters by giving values of compression load, sliding velocity and microscopic friction coefficient.

Ziegltrum et al. [3] use TEHD (thermo-elastohydrodynamic lubrication) simulation to determine influences of lubricants on the gear losses that are load-dependent. The TEHL simulation is based on FEM; it simulates contact along the contact path of the spur gears. The thermal effect for realistic prediction of the friction coefficient is taken into consideration.

Milošević et al. [4] present an approach for determination of residual stress in the rail wheel during quenching process. Residual stress is estimated using FEM thermal simulation with relatively high precision.

Pech [5] uses the FEM approach to calculate temperature distribution of worm gear transmission with worm gear made of plastic and worm made of steel. He has used limited input parameters; some of them he has obtained experimentally, with the intention to determine heat transfer coefficient $\alpha$.

Abukhshim et al. [6] give reviews of the temperature measurement methods and the analytical and numerical models for predicting temperature and temperature distribution in metal cutting. FEM is used as a numerical approach for predicting heat generation and temperature.

Taburdagitan et al. [7] investigate frictional heat during meshing spur gear pair with coupled thermo-elastic finite element analysis. The numerical results obtained by the finite element analysis yield high temperatures in comparison with the experimental results.

Berger et al. [8] investigate standardized wear and temperature prediction for worm gears under non-steady operating conditions and develop new calculation methodology that is proposed for DIN 3996.

The novelty of this paper lies in predicting temperature distribution for the whole transmission including lubricant, gears, shafts and housing using FEM by giving analytically calculated heat according to DIN 3996 input, as well as thermal parameters such as thermal conductivity, specific heat capacity and coefficient of thermal expansion in realistic geometry. This approach does not need any experiment in order to calculate temperature distribution but the results reported here are confirmed by the experimentally obtained temperatures. 


\section{TEST CONDITIONS}

The experiment is performed on worm gear transmission with centre distance of $30 \mathrm{~mm}$. Bearing of the worm shaft is done with two ring ball bearings with angular contact 7302 $\mathrm{BEP}$ with $\mathrm{X}$ arrangement. Position of the worm is under the worm gear. Temperature of oil is measured with Ni-Cr-Ni thermocouple, which is set just below the worm near the contact of worm gear set. Bearing of the worm gear shaft is done with two ring single row ball bearings with radial contact 6007 2RS1 and 6302 2RS1. The test bench for the worm gears and the position of the measuring points is shown in Fig. 1.

Drive of the test bench is performed via asynchronous power engine $2.5 \mathrm{~kW}$. The output torque goes via magnetic coupling, which can take up to torque of $160 \mathrm{Nm}$. Input and output coupling of gear transmission is carried out with gear coupling.

Temperature of the worm on the input side of the transmission is done over an infrared thermal element. The data of the worm gear (Fig. 2) are given in Table 1.

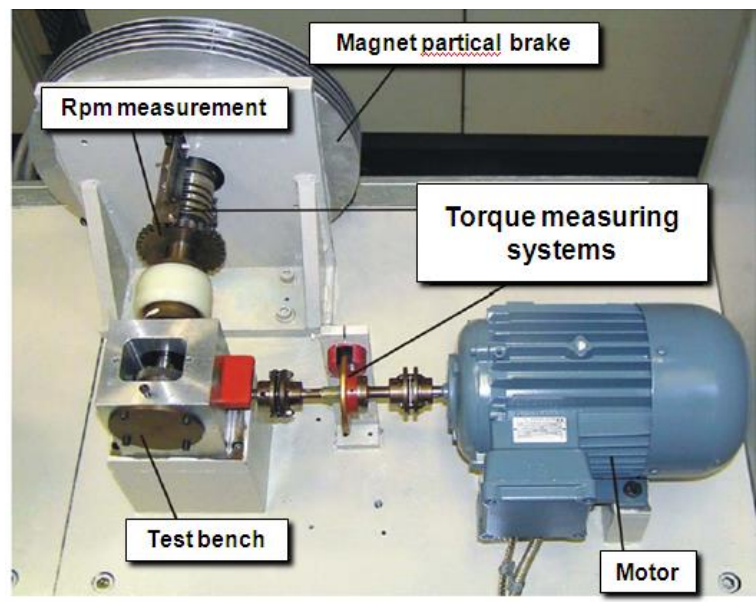

Fig. 1 Test bench

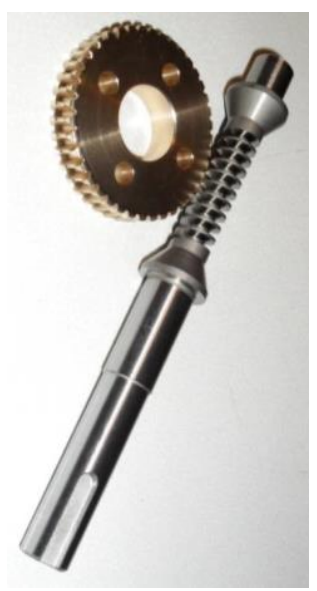

Fig. 2 Worm gear set

Table 1 Transmission gear parameters

\begin{tabular}{lc}
\hline Parameter & Values \\
\hline Centre distance $a[\mathrm{~mm}]$ & 30 \\
Worm gears type & ZI- DIN 3975 \\
Transmission ratio $i$ & 40 \\
Modul $m_{x}[\mathrm{~mm}]$ & 1.2608 \\
Number of teeth $\mathrm{z}_{1} / \mathrm{z}_{2}$ & $1 / 40$ \\
Wheel material & CuSn12Ni2-C-GCB \\
Worm material & $16 \mathrm{MnCr} 5$ \\
Input speed $\left[\mathrm{min}^{-1}\right]$ & 5000 \\
Torque $[\mathrm{Nm}]$ & $10-22$ \\
Synthetic oil GH6-1500 & $v_{40}=1500 \mathrm{~mm}^{2} / \mathrm{s} ; v_{100}=232 \mathrm{~mm}^{2} / \mathrm{s}$ \\
\hline
\end{tabular}




\section{EFFICIENCY}

\subsection{Overall efficiency of a transmission gear}

Efficiency of the transmission gear is a very important parameter of transmission quality. The overall efficiency of transmission gear $\eta_{\Sigma}$ can be determined with values of measured output torque values $T_{2}$ and input torque values $T_{1}$, i.e.:

$$
\eta_{\Sigma}=\frac{P_{2}}{P_{1}}=\frac{T_{2}}{T_{1} \cdot u}
$$

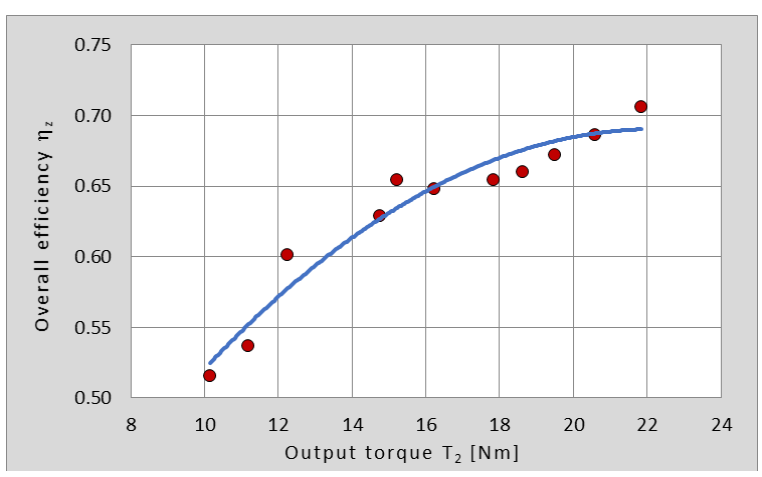

Fig. 2 Overall efficiency of the transmission for input speed $n_{1}=5000 \mathrm{~min}^{-1}$ and for different values of output torque $\mathrm{T}_{2}$

Figure 2 presents a diagram of dependency of transmission gear overall efficiency $\eta_{\Sigma}$ for input speed $n_{l}=5000 \mathrm{~min}^{-1}$ and for different values of output torque $T_{2}$. The output torque was changed via magnetic brake within the limits of the values from $T_{2}=10 \mathrm{Nm}$ to $T_{2}=22 \mathrm{Nm}$. At the same time, the transmission input and output torque values are measured, as well as oil and ambient temperature. The values of overall efficiency are determined according to equations (1); it is within the limits of the values: $\eta_{\Sigma}=0,52-0,71$. A trend of the output torque shows that, as the load increases, so does the overall efficiency.

\subsection{Power losses in bearings and seals}

Power losses in bearings and seals are determined according to the SKF bearing calculator, i.e. according to the SKF program module for determining power losses in bearings and seals [9].

The calculation results of a power loss in bearings for different values of output torque $T_{2}$ are shown in Fig. 3. Bearing A of the worm shaft is loaded with both axial and radial load. As result, the power losses at this bearing are the greatest by far. The worm gear shaft has a significantly smaller number of $\operatorname{rpm}\left(n_{2}=125 \mathrm{~min}^{-1}\right)$. Thus, the power loss in its bearings is significantly lower in comparison to the loss in the worm shaft bearings. With an increase in the load, the power losses in bearings increase as well. 


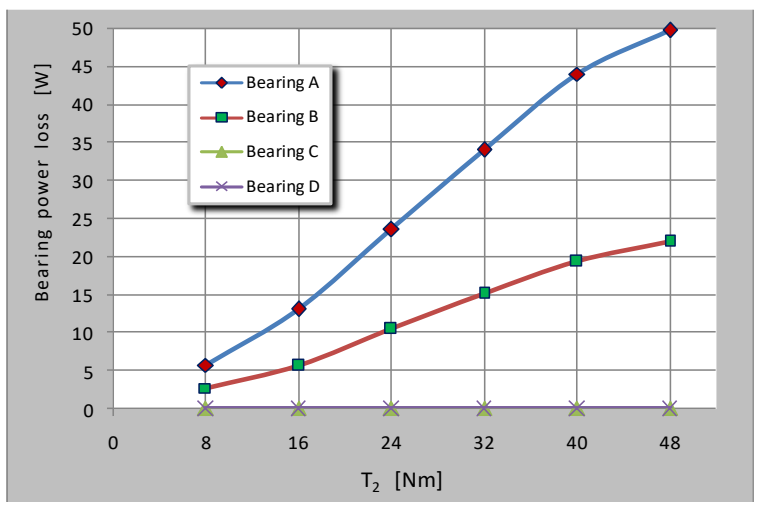

Fig. 3 Power losses in bearings for the determined operating oil temperature

The power losses increase along with the load. Considering that the aforementioned power loss converts into heat, the operating oil temperature changes as well. With a change in the operating oil temperature, oil viscosity changes as well. Power losses depend on oil viscosity. Consequently, the calculation of the power losses in bearings is carried out for the predicted values of the operating oil temperature. Thus, the obtained interdependence between power losses and load is not linear (Fig. 3). One can also notice that the impact of the load on the efficiency is significantly higher that the impact of a change in the oil's kinematic viscosity.

\section{DETERMINATION OF Working TEMPERATURE - ANALYTICAL APPROACH}

In the gear mesh, friction causes heat generation in gear flanks of worm pair. Tooth mass temperature is higher comparing to working oil temperature $\Delta \vartheta_{M}$ :

$$
\vartheta_{M}=\vartheta_{S}+\Delta \vartheta_{M}
$$

Increase in temperature of gear tooth $\Delta \vartheta_{M}$ depends on power losses in worm pair $P_{G z}$. According to the DIN $3996[10] \Delta \vartheta_{M}$ can be calculated as:

$$
\Delta \vartheta_{M}=\frac{P_{G z}}{\alpha_{L} \cdot A_{R}}
$$

where $P_{G z}$ are mesh power losses, $\alpha_{L}$ is heat transfer coefficient and $A_{R}$ cooling surface of the worm gear pair.

Mesh power losses $P_{G z}$ are experimentally determined depending on load or they can be calculated by reduction of overall power losses with power losses in bearings and seals:

$$
P_{G z}=P_{1}\left(1-\eta_{\Sigma}\right)-P_{G L D}
$$

According to the DIN 3996 [10], heat transfer coefficient $\alpha_{L}$ is calculated in function of input speed $n_{l}$ :

$$
\alpha_{L}=c_{k} \cdot\left(1940+15 \cdot n_{1}\right)
$$


Coefficient $c_{k}$ has values: $c_{k}=1$ for worm gear immersed in oil; $c_{k}=0,8$ for worm immersed in oil. Cooling surface of worm gear pair $A_{R}$ is calculated in function of worm gear width $b_{2 R}$ and medium diameter $d_{m 2}$ according to [10]:

$$
A_{R}=b_{2 R} \cdot d_{m 2} \cdot 10^{-6}
$$

Temperature of tooth mass $\vartheta_{M}$ is calculated according to equation (2) for different values of output torque $T_{2}$ is shown in Fig. 9. The trend line shows that there is linear dependence between temperature of tooth mass $\vartheta_{M}$ and output torque $T_{2}$. Temperature of tooth mass $\vartheta_{M}$ is increasing along with increasing output torque $T_{2}$ as an effect of increased power losses. Friction coefficient of the worm gear pair is experimentally determined for values of output torque $T_{2}=10 \mathrm{Nm}$ to $T_{2}=22 \mathrm{Nm}$.

\section{DETERMINATION OF TEMPERATURE DistribUtion IN THE WORM GEAR SET USING FEM}

The distribution of temperature in the worm gear transmission using FEM is done with the ANSYS Workbench software. The analysis is defined as a thermal analysis in the time domain that is used in the ANSYS module for transient thermal analysis. Worm and worm gear have complicate geometry; for generating the finite element mesh the elements of a higher order or SOLID 226 [11] are used. The mesh is generated with 5096742 nodes which form 3633469 elements.

In the continuous operation mode of the worm gear transmission a complex temperature distribution occurs. The heat generated in the bearings and the worm gear mesh in a steady condition must be over the surface of the housing brought to the environment preferably without additional cooling. The temperature distribution between the heat source and the housing surface is determined by heat transfer. For heat conduction is authoritative thermal conductivity $\lambda$. In order to take into account the differential temperature in the heat transfer, heat transfer coefficient $\alpha$ must be determined. This coefficient depends on a number of parameters. Parameters and boundary conditions for FEM simulations are given in Table 2. Simulation is carried out for $n_{1}=5000 \mathrm{~min}^{-1}$ and for three cases of output torque: $T_{2}=21.84 \mathrm{Nm}, T_{2}=16.22 \mathrm{Nm}$ and $T_{2}=12.25 \mathrm{Nm}$.

Table 2 Parameters for FEM simulation

\begin{tabular}{lccccc}
\hline Parameter, boundary condition & Unit & Dimension & $\mathrm{T}_{2}=21.84 \mathrm{Nm}$ & $\mathrm{T}_{2}=16.22 \mathrm{Nm}$ & $\mathrm{T}_{2}=12.25 \mathrm{Nm}$ \\
\hline Power losses in worm gear set & $P_{G z}$ & $\mathrm{~W}$ & 69.91 & 51.93 & 39.21 \\
Power losses in bearing A & $P_{G L A}$ & W & 10.05 & 8.69 & 7.49 \\
Power losses in bearing B & $P_{G L B}$ & W & 21.99 & 18.85 & 15.97 \\
Power losses in bearing C & $P_{G L C}$ & W & 0.08 & 0.07 & 0.06 \\
Power losses in bearing D & $P_{G L D}$ & W & 0.02 & 0.02 & 0.02 \\
Power losses in sealing of bearings & $P_{G D}$ & W & 0.48 & 0.48 & 0.48 \\
\hline
\end{tabular}

Alongside the worm gear transmission model, it contains all the shafts, bearings, lubrication and housing. The FEM model for the thermal simulation is shown in Fig. 6. 




Fig. 4 FEM model of tested transmission

In Table 3 and Fig. 4 are given thermal characteristics of the material used in analysis. The analysis takes into account thermal characteristics that are depending on temperature for all materials.

Bearings power losses are determined by the SKF calculation [9] and introduced in the FEM model in the heat transfer. In addition to the measured value of ambient temperature $\vartheta_{0}$ it is necessary to determine power losses in the mesh of the worm gear pair as well as those in seals. The coefficient of heat transfer to the environment based on the data available research is $\alpha_{o k}=12-15 \mathrm{~W} / \mathrm{m}^{2} \mathrm{~K}[12,13]$, and for simulation is used $\alpha_{o k}=15 \mathrm{~W} / \mathrm{m}^{2} \mathrm{~K}$. Based on the generated power losses in the mesh of worm gear pair, bearings and seals, tooth mass temperature is determined by simulation and so is temperature distribution of the entire worm gearing as well as temperature of housing or some other element of transmission.

Table 3 Thermal characteristics of material used in analysis

\begin{tabular}{lcccc}
\hline Material & & $\begin{array}{c}\text { Specific heat capacity } \\
{[\mathrm{J} /(\mathrm{kg} \mathrm{K})]}\end{array}$ & $\begin{array}{c}\text { Thermal conductivity } \\
{[\mathrm{W} /(\mathrm{m} \mathrm{K})]}\end{array}$ & $\begin{array}{c}\text { Coefficient of thermal } \\
\text { expansion }\left[\mathrm{K}^{-1}\right]\end{array}$ \\
\hline 16MnCr5 & & 434 & 60.5 & $1.2 \cdot 10^{-5}$ \\
CuSn12Ni2 & $20^{\circ} \mathrm{C}$ & 376 & 50 & $17.2 \cdot 10^{-6}$ \\
-C-GCB & $100^{\circ} \mathrm{C}$ & 385 & 56 & \\
\hline
\end{tabular}




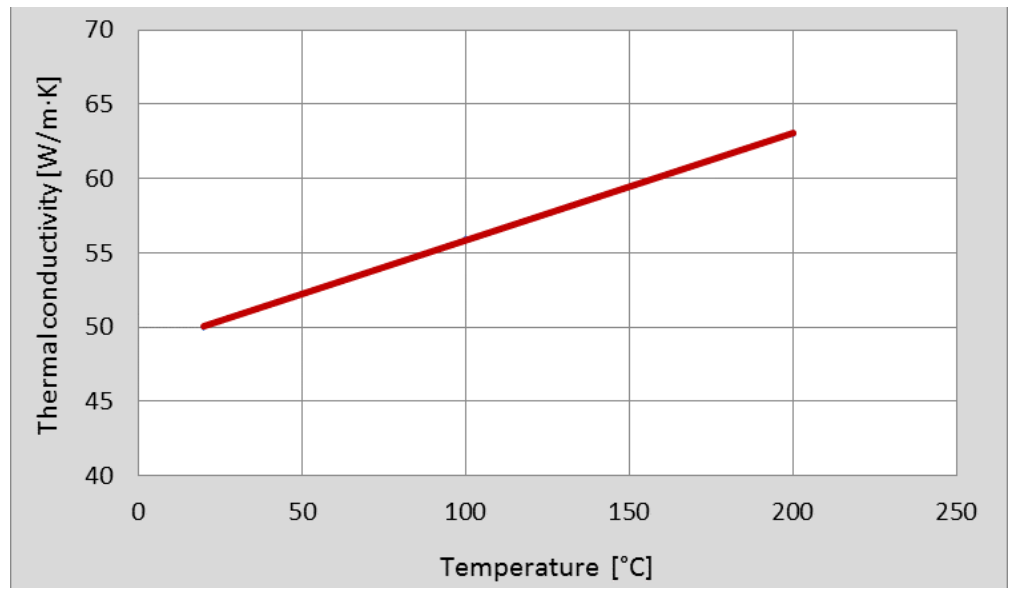

Fig. 5 Thermal conductivity for CuSn12Ni2-C-GCB

The generated heat in the transmission goes into the surrounding environment over a relatively large area of housing, and over a part of the foundation. The ends of the shafts have a relatively small area and over them heat goes into the environment. Since the worm gear shaft rotates slowly, the share of heat that goes by convection over surface is small, so that when simulation is taken the same value of heat transfer coefficient of housing is obtained Although the heat transfer from the gear on the oil and air in the transmission is, by its nature, one of the convective processes, this process is approximated as a conductive one. The same approximation is made for contact of air and oil in the transmission and in the housing. That approximation is introduced because it has a small effect on the macroscopic temperature distribution.

In Figs. 6 a), b) and c) are shown the results of the temperature distribution of the transmission on worm gears (Figs. on the left) and the housing (Figs. on the right). In Fig. 6 (left) is given the distribution of temperature on the worm gear as one of the most important elements of the worm gear transmission. The Figs. show that the maximum temperature is in the mesh zone and in the rest of the volume of the worm gear temperature is relatively stable and in a range of few degrees. The highest temperature distribution is for $T_{2}=21.84 \mathrm{Nm}$ and temperature is in the range of $90-96^{\circ} \mathrm{C}$. For $T_{2}=16.22 \mathrm{Nm}$ it is in the range of $80-87{ }^{\circ} \mathrm{C}$ and for $T_{2}=12.25 \mathrm{Nm}$ it is in the range of $72-77{ }^{\circ} \mathrm{C}$.

Figure 6 (on the right) shows that the housing depends on the output torque. The highest temperature distribution is for $T_{2}=21.84 \mathrm{Nm}$ and temperature is in the range of 58$61{ }^{\circ} \mathrm{C}$. For $T_{2}=16.22 \mathrm{Nm}$ is in the range of $53-56{ }^{\circ} \mathrm{C}$ and for $T_{2}=12.25 \mathrm{Nm}$ is in the range of $48-51^{\circ} \mathrm{C}$ 

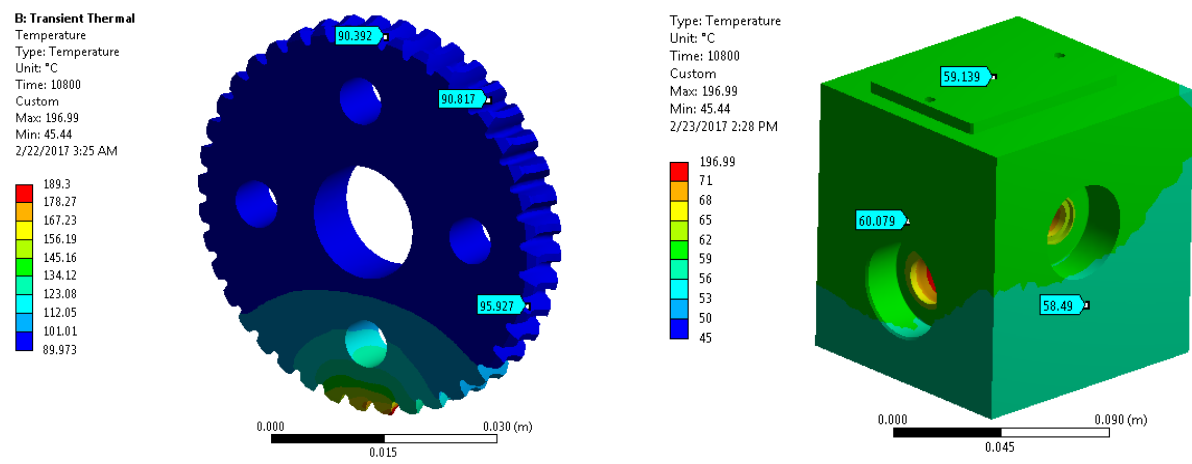

a)
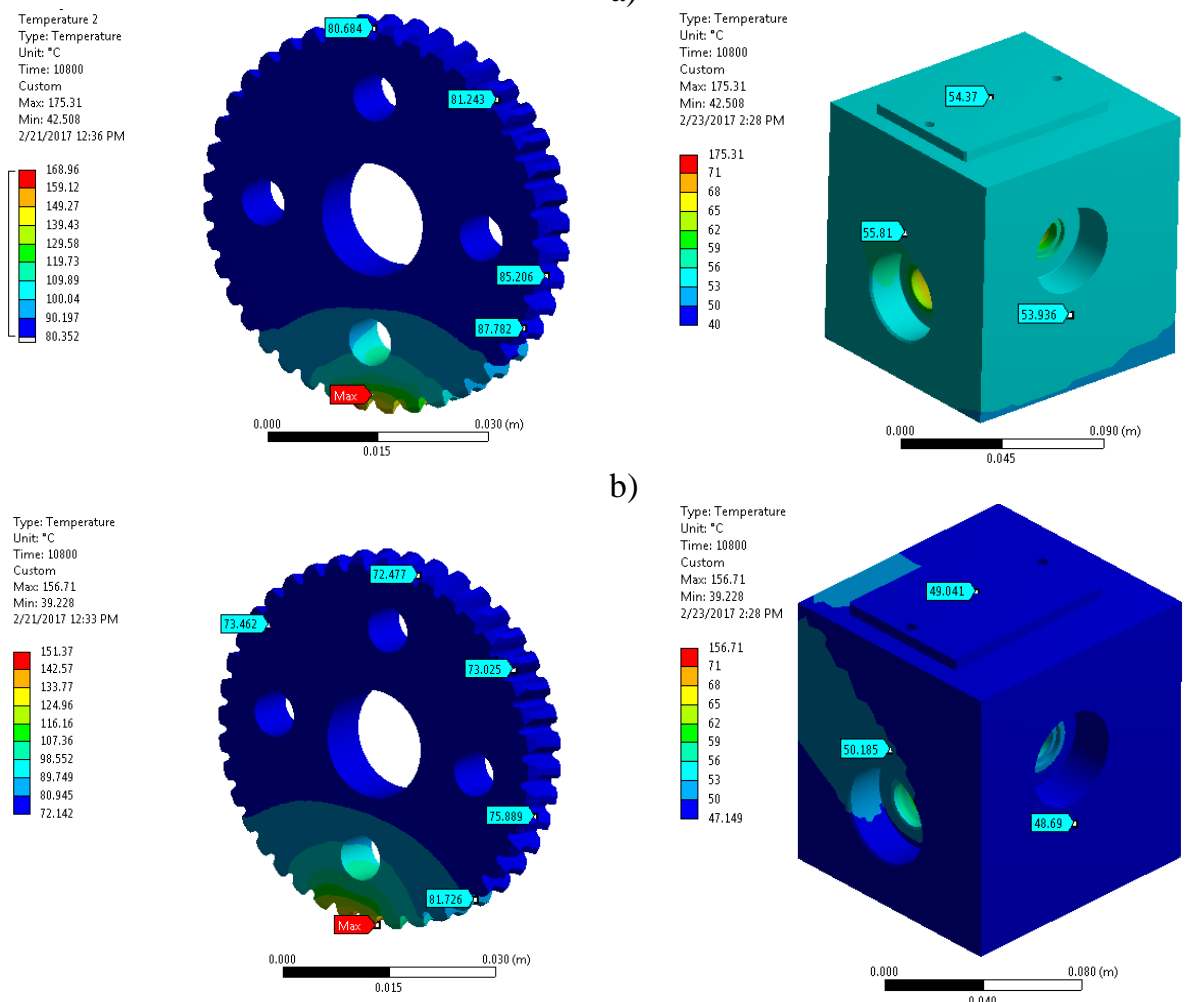

c)

Fig. 6 Temperature distribution at worm gear and housing for $\mathrm{n}_{1}=5000 \mathrm{~min}^{-1}$ and: a) $\left.\left.\mathrm{T}_{2}=21.84 \mathrm{Nm}, \mathrm{b}\right) \mathrm{T}_{2}=16.22 \mathrm{Nm}, \mathrm{c}\right) \mathrm{T}_{2}=12.25 \mathrm{Nm}$

Tooth mass temperature obtained by simulation is largely consistent with experimentally determinate value - Fig. 7. From the above it can be concluded that it is correctly assumed that on the basis of certain analytically determinate power losses in the transmission the temperature distribution of the entire transmission in exploitation using the finite element method can be estimated. 


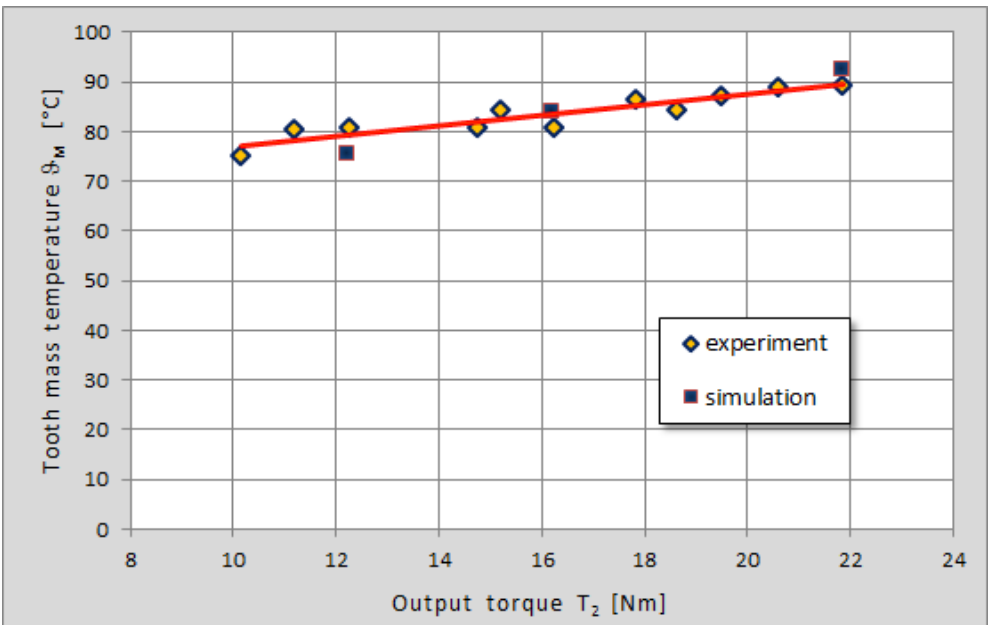

Fig. 7 Comparison of tooth mass temperature obtain by experiment and simulation

Fig, 8 shows the distribution of temperature in the cross section of the transmission oil. Numeric values of specified temperatures are in the range from $125.2{ }^{\circ} \mathrm{C}$ to $59.93{ }^{\circ} \mathrm{C}$. Maximum temperature of $125.2{ }^{\circ} \mathrm{C}$ is obtained in the mesh of worm gear pair and it represents the current temperature at the contact point flanks, which is consistent with similar studies in this area [15].

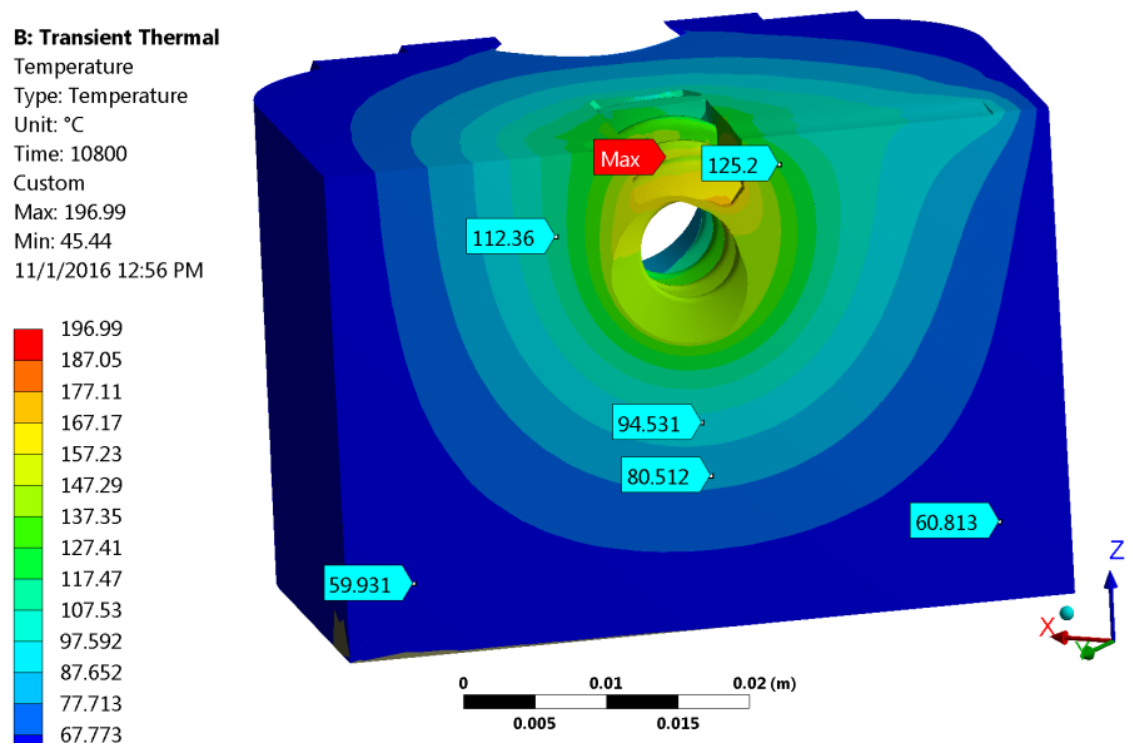

Fig. 8 Temperature distribution in the cross section of transmission oil for $T_{2}=21.84 \mathrm{Nm}$ and $n_{l}=5000 \mathrm{~min}^{-1}$ 


\section{CONCLUSION}

This study is focused on the determination of temperature distribution in the worm gear transmission.

Based on the generated analytically determined power losses in the mesh of worm gear pair, bearings and seals, simulation is applied to determine tooth mass temperature, temperature distribution of the entire worm gearing as well as other elements of transmission.

The obtained results show a high degree of correlation results obtained experimentally and numerically.

With this approach it is possible to examine thermal state of the complete transmission and identify critical points in terms of heating and successful fulfillment of the work functions of the transmission. This is of great significance for engineering practice because it offers the possibility, in the design stage of the transmission, to receive relevant information about the behavior of the transmission in the exploitation conditions and to promptly make the necessary correction structure without costly and time-consuming prototype testing.

\section{REFERENCES}

1. Jain, R., Pal, K.S., Singh, B.S, 2016, A study on the variation of forces and temperature in a friction stirwelding process: A finite element approach, Journal of Manufacturing Processes, 23, pp. 278-286.

2. Haddad, H., Guessasma, M., Fortin, J., 2016, A DEM-FEM coupling based approach simulating thermomechanical behavior of frictional bodies with interface layer, International Journal of Solids and Structures, 81, pp 1-16.

3. Ziegltrum, A., Lohner, T., Stahl, K., 2017, TEHL Simulation on the Influence of Lubricants on LoadDependent Gear Losses, Tribology International, 113, pp. 252-261.

4. Milošević, M., Miltenović, A., Banić, M., Tomić, M., 2017, Determination of Residual Stress in the Rail Wheel During Quenching Process by FEM Simulation, Facta Universitatis-Series Mechanical Engineering, 15(3), pp. 413-425.

5. Pech, M., 2011, Tragfähigkeit und Zahnverformung von Schraubradgetrieben der Werkstoffpaarung Stahl/Kunststoff, Dissertation Ruhr-University Bochum

6. Abukhshim, N.A., Mativenga, P.T., Sheikh, M.A., 2006, Heat generation and temperature prediction in metal cutting: A review and implications for high speed machining, International Journal of Machine Tools and Manufacture, 46(7-8), pp. 782-800.

7. Taburdagitan, M., Akkok, M., 2006, Determination of surface temperature rise with thermo-elastic analysis of spur gears, Wear 261, pp. 656-665.

8. Berger, M., Sievers, B., Hermes, J., 2015, Standardized Wear and Temperature Prediction for Worm Gears under Non-Steady Operating Conditions, International Conference Gears. VDI-Society for Product and Process Design, Munich, Germany, VDI Berichte 2255.1, pp.483-492.

9. SKF, 2014, Hauptkatalog, Das Wälzlager-Handbuch für Studenten Neuwertig,

10. DIN 3996, 2012, Tragfähigkeitsberechnung von Zylinder Schneckengetrieben mit sich rechtwinklig kreuzenden Achsen.

11. ANSYS Inc., 2010, ANSYS theory manual, USA.

12. Böge, A., 2011, Handbuch Maschinenbau: Grundlagen und Anwendungen der Maschinenbau-Technik. Springer Fachmedien Wiesbaden,.

13. Cerbe, G., Wilhelms, G., 2010, Technische Thermodynamik: Theoretische Grundlagen und praktische Anwendungen. Gebundene Ausgabe - Hanser.

14. Klübersynth GH 6, 2014, Synthetic gear and high temperature oils based on KlüberComp Lube Technology

15. Lange, N., 2000, Hoch fresstragfähige Schneckengetriebe mit Rädern aus Sphäroguss, Dissertation TU München. 